\title{
The relation of left internal mammary artery atherosclerosis with urotensin-II
}

\author{
Bahar $\mathrm{L}^{1}$, Tuysuz $\mathrm{ME}^{2}$ \\ Department of Medical Services and Techniques of Vocational School, Mersin University, Yenisehir Campus, \\ Yenisehir-Mersin, Turkey. leylabahar@mersin.edu.tr
}

\begin{abstract}
BACKGROUND: The aim of our study is to investigate the effects of urotensin-II (U-II) on the left internal mammary artery (LIMA) wall and role of $U$-II in atherosclerotic processes affecting the long-term patency of LIMA.

METHOD: Patients were divided into 2 groups, namely Group I: patients with coronary artery disease (CAD) and Group II: DM + CAD. The patients were evaluated by Gencini scoring before coronary artery bypass grafting (CABG). Routine tissue follow-up, hemotoxylin-eosin staining and immunoreactivity with U-II were observed. Then, vessel damage score, $\mathrm{H}$-Score and LIMA layer thickness were calculated and evaluated statistically.

RESULTS: On light microscopic examination, the LIMA total damage score in DM + CAD group was significantly higher compared to the control group. The assessment of $\mathrm{H}$ score revealed that $\mathrm{U}$-II was more intense in tunica intima and tunica media in the DM+CAD group as compared to the control group $(p<0.05)$. Furthermore, tunica intima and tunica media in the DM + CAD group were thicker than in the control group $(p<0.05)$.

CONCLUSIONS: We found that U-II is effective in atherosclerotic processes of arterial grafts. The DM + CAD group has high U-II density with high total damage score in intima and media layers of LIMA. U-II may be effective in late survival results after CABG (Tab. 3, Fig. 2, Ref. 19). Text in PDF www.elis.sk KEY WORDS: coronary artery disease, left internal mammary artery, atherosclerosis. urotensin II, diabetes mellitus.
\end{abstract}

\section{Introduction}

Diabetes mellitus (DM) is an important risk factor that increases mortality and morbidity, while leading to long-term poorly outcomes in coronary artery disease patients (1). The use of internal mammary artery (IMA) for coronary grafts is currently considered the gold standard in the classic surgical approach. Therefore, the guidelines of the European Society of Cardiology on myocardial revascularization (2014) strongly supports the use of IMA grafts (2). Urotensin-II (U-II) levels have been shown to increase, particularly in diabetes mellitus-associated atherosclerosis (3). Urotensin-II receptor antagonism may become a promising therapeutic strategy for the treatment of atherosclerosis (4).

We performed immunohistochemical analysis to investigate the effects of urotensin-II on the LIMA wall as we think that urotensin-II is involved in atherosclerotic processes acting in the long-term patency of LIMA. We aimed to reveal the atheroscle-

${ }^{1}$ Department of Stem Cell and Regenerative Medicine, Mersin University, Mersin, Turkey, and ${ }^{2}$ Department of Cardiovascular Surgery, Mersin City Training and Research Hospital, Mersin, Turkey

Address for correspondence: L. Bahar MD, PhD, Department of Medical Services and Techniques of Vocational School, Mersin University, Yenisehir Campus, Yenisehir-Mersin/Turkey .

Phone: +905057984143, Fax: +90 3242346410 rosis-associated histopathological features of the arterial grafts to improve late survival after CABG. To the best of our knowledge, this is the first article in literature to demonstrate the involvement of urotensin in atherosclerotic processes in human LIMA.

\section{Materials and methods}

Study Design

Before starting the study, an approval of the Mersin University Clinical Research Ethics Committee was obtained with registration date/number of 19.10.2018/499. The study specimens were obtained from the total of 21 patients aged 30 to 80 years, who met the inclusion criteria and who were admitted to the outpatient clinic of the Cardiovascular Surgery Department of Mersin City Training and Research Hospital in the period from October 2018 to March 2019 with the indication to undergo CABG surgery. Informed consent documents were obtained from all of the participating patients. Arterial tissue samples of 1-2 cm in length were used in the study and these samples were taken from the left internal mammary artery (LIMA) prepared for CABG.

The inclusion criteria were as follows: assessment of the diagnosis of coronary artery disease (CAD) at age in range of 30 to 80 years, at least two coronary artery lesions to comply with the indication to undergo coronary artery bypass surgery, graft planned with the use of LIMA, no history of recent corticosteroid use, no 
Tab. 1. The comparison of demographic characteristics and Gensini score of the study groups.

\begin{tabular}{|c|c|c|c|c|}
\hline Variables & $\begin{array}{l}\text { All patients } \\
(\mathrm{n}=21)\end{array}$ & $\begin{array}{l}\text { Without DM } \\
+ \text { CAD }(n=8)\end{array}$ & $\begin{array}{l}\text { With DM+CAD } \\
\qquad(\mathrm{n}=13)\end{array}$ & $\mathrm{p}$ \\
\hline Age (y) & $62.7 \pm 8.2$ & $59.7 \pm 6.8$ & $64.2 \pm 8.6$ & 0.25 \\
\hline Gender (Male-Woman) & $\begin{array}{c}17(85.0) \\
4(15.0)\end{array}$ & $\begin{array}{l}6(85.7) \\
2(14.3)\end{array}$ & $\begin{array}{l}11(84.6) \\
2(15.4)\end{array}$ & 0.73 \\
\hline Height (m) & $1.7(1.7-1.7)$ & $1.7(1.7-1.7)$ & $1.7(1.6-1.7)$ & 0.88 \\
\hline Weight (kg) & $77(73-80)$ & $77(73-84)$ & $76(72-80)$ & 0.70 \\
\hline $\operatorname{BSA}\left(\mathrm{m}^{2}\right)$ & $1.9 \pm 0.1$ & $1.9 \pm 0.1$ & $1.9 \pm 0.2$ & 0.75 \\
\hline Waist circumference $(\mathrm{cm})$ & $61.4 \pm 31.7$ & $75.6 \pm 37.2$ & $54.2 \pm 27.4$ & 0.19 \\
\hline BMI $\left(\mathrm{kg} / \mathrm{m}^{2}\right)$ & $27.3 \pm 3.3$ & $27.6 \pm 1.5$ & $27.1 \pm 4.0$ & 0.74 \\
\hline Triglycerides (mg/dL) & $166.9 \pm 69.6$ & $150.7 \pm 57.7$ & $175.6 \pm 76.0$ & 0.47 \\
\hline Cholesterol (mg/dL) & $165.5 \pm 51.9$ & $163.7 \pm 52.1$ & $166.7 \pm 54.5$ & 0.91 \\
\hline $\mathrm{HDL}(\mathrm{mg} / \mathrm{dL})$ & $39.5 \pm 7.1$ & $40.8 \pm 3.0$ & $38.9 \pm 8.5$ & 0.57 \\
\hline LDL (mg/dL) & $92.6 \pm 40.9$ & $92.6 \pm 45.0$ & $92.5 \pm 40.4$ & 0.99 \\
\hline VLDL (mg/dL) & $32.9 \pm 13.3$ & $30.2 \pm 11.6$ & $34.4 \pm 14.4$ & 0.51 \\
\hline Creatinine (mg/dL) & $0.88 \pm 0.41$ & $0.85 \pm 0.38$ & $0.98 \pm 0.48$ & 0.52 \\
\hline Uric acid & $7.4 \pm 2,2$ & $6.9 \pm 2.1$ & $8.1 \pm 2.4$ & 0.25 \\
\hline \multirow[t]{2}{*}{ Gensini Score } & Gensin & $\begin{array}{l}\text { sini score categ } \\
\text { re }<20 \text {, Gensin }\end{array}$ & core $\geq 20$ & \multirow{3}{*}{0.006} \\
\hline & $\begin{array}{l}\text { All patients } \\
\quad(\mathrm{n}=21)\end{array}$ & $\begin{array}{l}\text { Without DM } \\
+ \text { CAD }(n=8)\end{array}$ & $\begin{array}{c}\mathrm{DM}+\mathrm{CAD} \\
(\mathrm{n}=13)\end{array}$ & \\
\hline $\begin{array}{l}\text { Mean rank } \\
\text { min-max }\end{array}$ & $\begin{array}{c}21.43 \\
(12-128)\end{array}$ & $\begin{array}{c}6.33 \\
(12-72)\end{array}$ & $\begin{array}{c}13.27 \\
(33-128)\end{array}$ & \\
\hline
\end{tabular}

CAD - coronary artery disease; BMI - body mass index; BSA - body surface area.
$\%$ formalin) to conduct examinations under the light microscope.

\section{Tissue monitoring with light microscopy}

Routine tissue monitoring procedures were applied at the Pathology Department of the Mersin City Training and Research Hospital to investigate the study specimens. Sections of $5 \mu \mathrm{m}$ in thickness were taken from prepared paraffin blocks using Leica RM-2245. The sections were stained with routine hematoxylin-eosin staining $(\mathrm{H}+\mathrm{E})$ to reveal the general characteristics of LIMA tissue, and with urotensin II (U-II) to evaluate the tissue for immunoreactivity.

\section{Immunohistochemistry}

First, the tissue samples fixed in $10 \%$ formalin were embedded in paraffin after carrying out the routine procedures. Sections of 5-6 $\mu \mathrm{m}$ in thickness were taken. Of these tissue sections, some were stained with $\mathrm{H}+\mathrm{E}$ stain while some underwent im-

diagnosis of peripheral arterial disease (ankle-brachial index: 0.91.40 ), fasting blood glucose (FBG) levels of $\geq 126 \mathrm{mg} / \mathrm{dL}$, and/or HbA1c levels of $\geq 6.4(\%)$ indicating DM.

\section{Study Groups}

Group 1 (CAD; control group): LIMA specimens obtained from atherosclerotic coronary artery patients with no diagnosis of DM.

Group 2 (DM+CAD; case group): LIMA specimens obtained from atherosclerotic coronary artery patients with Type 2 DM.

\section{Surgical technique}

The patient specimens included in the study were pedicled LIMA grafts described as LIMA grafts harvested with the intrathoracic fascia, veins, adipose tissue, and sometimes muscle tissue around the artery. Pedicled LIMA harvesting can be associated with arterial spasms and injuries less commonly since the arterial contact is minimal or absent in this type of graft (5). LAD-LIMA anastomosis was performed using the on-pump CABG technique.

\section{Histopathological examination}

Collecting waste tissue samples after the coronary artery bypass surgery

In our study, the LIMA tissue specimens from atherosclerotic CAD patient were collected primarily in compliance with CABG principles. The parts of LIMA grafts not used in CABG surgery were subjected to examination. LIMA of each patient was exposed by the same surgeon using the aforementioned artery preparation technique. After the preparation of grafts, atraumatic tissue specimens of 1-2 cm in length were obtained from the unused LIMA graft parts. As soon as the tissue specimens for the study had been collected, they were placed in an appropriate fixative solution (10 munohistochemical staining. Deparaffinization and rehydration of the sections were performed to prepare them for the immunohistochemical staining. Respectively, rehydration process and antigen retrieval processes were performed. The sections were incubated at $+4{ }^{\circ} \mathrm{C}$ for 20 hours with U-II primary antibody at $1 / 150$ dilution. Biotinylated secondary antibody and streptavidin-peroxidase enzyme conjugate (20 minutes) were administered, respectively. Then, 3-amino-9-ethyl carbazole (AEC) chromogen was used. Contrast staining was performed with Mayer's hematoxylin solution and the tissue sections were covered with the mounting medium, LabVision, TA-060-UG. Then, the slides were made ready for examination under the light microscope.

\section{Evaluation of the tissue preparations}

The tissue sections were examined under a light microscope (Olympus BX53) to evaluate the morphological structure of the vessel layers (tunica intima, tunica media, and tunica adventitia) and investigate whether the cells were intact. Furthermore, the sections were analyzed in terms of intensity immunoreactivity. NIS-Elements Documentation 4.5 image analysis system and DP26 camera system were used for photographing. At least 20 fields were examined in each tissue preparation under $20 \mathrm{X}$ magnification to calculate the average number of damaged cells. Then, any damage in endothelium, internal elastic lamina, or smooth muscle cell in the tunica media were scored as follows: none $=0$, mild findings in focal areas $=1$, moderately common and in moderate severity $=2$, widespread and severe $=3$. The maximum possibly attainable total score was 9 .

After the immunohistochemical staining, H-scores (density of immunoreactivity) were calculated in a modified form described by Ozcan-Kucuk et al (6). 


\section{$516-521$}
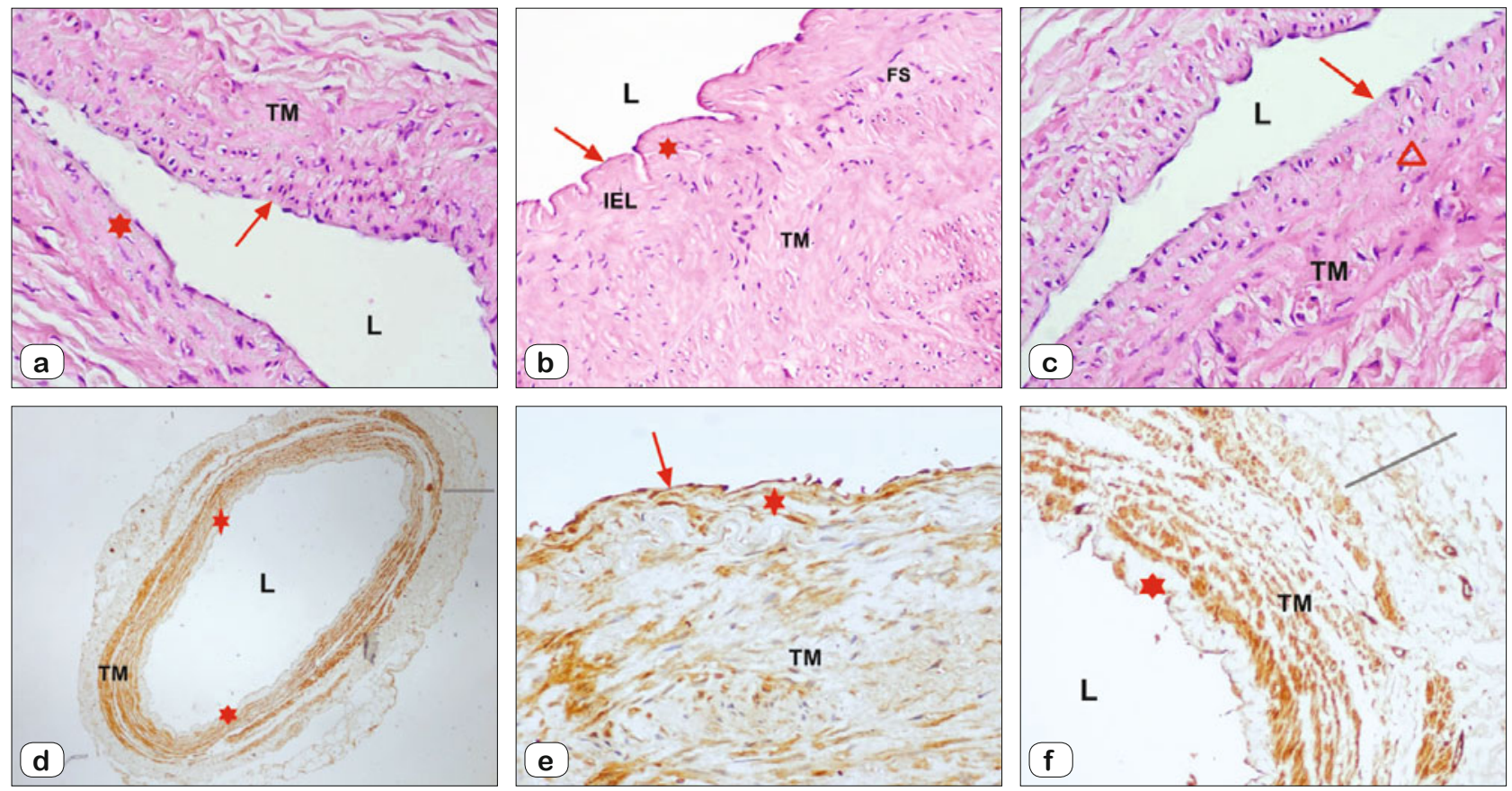

Fig. 1. The sections of Group 1 (CAD; Control group) are examined. Artery sections stained with H\&E (Fig. 1 a,b,c) and some parts stained for immunoreactivity with urotensin-II (Fig. 1 d,e,f) are shown. Endothelial cells, media layer, smooth muscle cells, and IEL were evaluated as in normal structure.

Rightward-pointing arrow: endothelial cells; upward-pointing arrow: foam cells; star: tunica intima; TM: tunica media; straight line: tunica adventitia; IEL: internal elastic lamina; FS: fatty streak; L: lumen, H\&E, U-II; scale bar: $50 \mu \mathrm{m}, 100 \mu \mathrm{m}$.
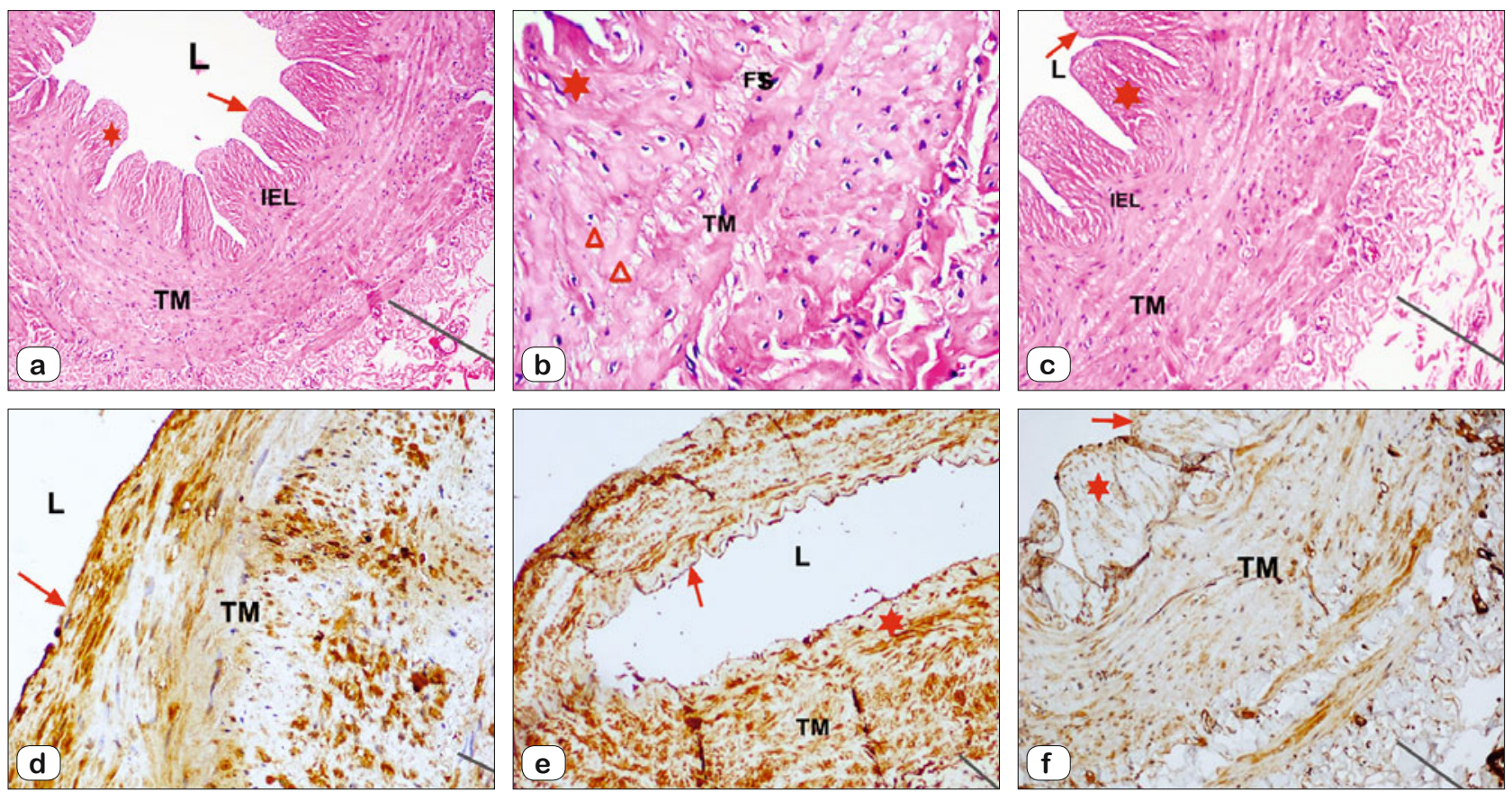

Fig. 2. Group 2 (DM+CAD; case group): Artery sections stained with H\&E (Fig. 2 a,b,c) and urotensin-II (Fig. 2 d,e,f). The figure shows damaged endothelial areas, loss in regular structure in IEL and corruptions occurring in some of its regions. SMCs in the tunica media do not maintain their normal structure; there are changes in cell morphology and localization in many areas, and significant separations in the layer. Rightward arrow: endothelial cells; arrow head: foam cells, star: tunica intima, TM: tunica media; straight line: tunica adventitia; IEL: internal elastic lamina; FS: fatty streak; L: lumen; H\&E; U-II; scale bar: $50 \mu \mathrm{m}, 100 \mu \mathrm{m}$. 
Assessment of the severity of coronary artery stenosis

According to the results from the coronary angiography, Gensini scoring was used for estimating the severity of coronary artery stenosis in each patient. Modified Gensini scores were calculated for each study patient as specified in the study of Beypinar et al. To grade the severity of the coronary atherosclerosis, the average Gensini scores were categorized into two groups, using the cutoff point between the "mild-to-absent" and "moderate-to-severe" coronary atherosclerosis $(7,8)$. Then, the scores were summed to obtain a single numeric value for each patient.

\section{Statistical analysis}

The statistical analyses were performed using the SPSS (Statistical Package for Social Sciences) software. Continuous variables conforming to a normal distribution were presented as mean \pm standard deviation, while those not conforming to normal distribution were presented as median. The Mann-Whitney U test was used for comparing two groups. A p-value of $<0.05$ was considered statistically significant. Assuming the type-I error with the alpha value of 0.05 and the test power of 0.80 , the minimum sample width for each group was calculated to be 9 for this study.

\section{Results}

The LIMA tissue samples of Group I (control group) and Group II (case group) were examined under the light microscopic examination and the results were evaluated.

\section{Group I (CAD)}

The arterial tissue sections stained with H\&E generally appeared normal despite some mild degeneration and loss in epithelial cells and smooth muscle cells in the tunica media. The architecture of elastic laminae was considered natural. Foam cells, indicating the atherosclerotic processes, were observed at spaces in the subendothelial areas (Fig. 1a, b, c). In the sections stained with U-II immunohistochemistry, it was observed that the intima layer was regular and the endothelial cells retained their architecture. The subendothelial layer was thin in most parts. The inner elastic membrane was observed as indented, while the smooth muscle cells and collagen fibers had normal architecture. It was observed that the endothelial cells were stained distinctly and very strongly with U-II immunoreactivity. Although tunica intima and tunica adventitia showed moderate immunoreactivity, it was observed that the immunoreactivity in the former showed to be more intense (Fig. 1d, e, f).

\section{Group II $(C A D+D M)$}

$\mathrm{H}+\mathrm{E}$ staining and immunoreactivity with U-II of the tissue specimens revealed a loss in continuity in the endothelial layer, damaged endothelial cells at spaces, and disruptions at areas against the lumen. The examination of endothelial cells under a high magnification showed that the vesicles in the apical and basal cell membranes were more common when compared to the control group. It was noted that the subendothelial layer was expanded at spaces and these areas were protruded towards the lumen. The abundance of collagen fibers increased in the subendothelial layer which was thicker compared to that in the control group. It was observed that the internal elastic lamina had lost its regular structure and undulating pattern, while displaying interruptions. Also, fatty streaks were observed in association with foam cells of the subendothelial layer (Fig. 2 a,b,c).

The morphology of smooth muscle cells in tunica media was deteriorated while invading tunica intima with distinct interruptions. The U-II immunoreactivity was more intense in tunica intima and tunica media when compared to the control group $(\mathrm{p}<0.05)$. Furthermore, intensely positive U-II immunoreactivity was observed in tunica adventitia (Fig. 2 d,e,f, Tab. 2) $(\mathrm{p}<0.05)$. The thickness of tunica intima and tunica media in the study groups was measured and compared with the use of Mann-Whitney U test. Tunica intima and tunica media of the vessels were thicker in the $\mathrm{DM}+\mathrm{CAD}$ group as compared to the control group (Tab. 3) $(\mathrm{p}<0.05)$. There were no further statistically significant differences between the groups in terms of demographic characteristics of patients (hypertension, hyperlipidemia, smoking, redo coronary surgery, family history of CAD, preoperative atrial fibrillation) and postoperative one-year follow-up results (redo coronary surgery, angina pectoris, re-hospitalization, NYHA classification, mortality; $\mathrm{p}>0.05)$.

Tab. 2. The comparison of total damage scores and H-score of the study groups.

\begin{tabular}{lccccccc}
\hline \multirow{2}{*}{ LIMA-U-II } & $\begin{array}{c}\text { Endothelial } \\
\text { damage }\end{array}$ & $\begin{array}{c}\text { Damage in smooth } \\
\text { muscle cells in T. }\end{array}$ & $\begin{array}{c}\text { Damage in elastic } \\
\text { lamina in T. media } \\
\text { (Max: 3) }\end{array}$ & $\begin{array}{c}\text { Total Damage } \\
\text { media (Max: 3) }\end{array}$ & Score (Max: 9) & & \multicolumn{2}{c}{ H Score $=$ Pi (i+1) } \\
\cline { 6 - 9 } W. intima & T. media & T. adventitia \\
\hline Without DM+CAD(n:8) & $1.0 \pm 0.4$ & $1.0 \pm 0.3$ & $0.8(0.5-0.8)$ & $3.0(1.9-3.3)$ & $300 \pm 52.6$ & $240.0 \pm 54.8$ & $210.2 \pm 51.4$ \\
With DM+CAD(n:13) & $2.2 \pm 0.5$ & $2.3 \pm 0.2$ & $2.4(2.2-2.6)$ & $6.8(6.2-7.4)$ & $240 \pm 54.7$ & $357.1 \pm 53.5$ & $255.0 \pm 57.3$ \\
p & $0.001 *$ & $0.001^{*}$ & $0.004^{*}$ & $0.004^{*}$ & $0.026^{*}$ & $0.004^{*}$ & 0.085 \\
\hline
\end{tabular}

Tab. 3. Comparisons of Layer thickness of LIMA of groups (tunica intima and tunica media).

\begin{tabular}{lccc|cc}
\hline LIMA-U-II & \multicolumn{3}{c}{ Layer thickness of LIMA $(\mu \mathrm{m})$} \\
\cline { 2 - 6 } & $\begin{array}{c}\text { Tunica (T.) intima } \\
\text { minimum }\end{array}$ & $\begin{array}{c}\text { T. intima } \\
\text { maximum }\end{array}$ & $\begin{array}{c}\text { T. intima } \\
\text { mean }\end{array}$ & $\begin{array}{c}\text { T. media } \\
\text { minimum }\end{array}$ & $\begin{array}{c}\text { T. media } \\
\text { maximum }\end{array}$ \\
\hline Without DM+CAD(n:8) & $20.45 \pm 7.3$ & $33.96 \pm 11.4$ & $24.94 \pm 7.3$ & $46.33 \pm 28.9$ & $182.46 \pm 54.6$ \\
With DM+CAD(n:13) & $37.98 \pm 9.2$ & $47.87 \pm 5.2$ & $39.83 \pm 6.0$ & $112.25 \pm 18.5$ & $286.16 \pm 57.0$ \\
p & & $<0.05$ & & $227.93 \pm 49.6$ & $<0.05$ \\
\hline
\end{tabular}




\section{Statistical analysis}

The Mann-Whitney U test was used for comparing two groups. A p-value of $<0.05$ was considered significant. As seen in Table 1, the comparison of demographic characteristics and Gensini scores of groups were statistically significant. The mean and standard deviation values of the scores of damage found in endothelium, internal elastic lamina, and smooth muscle cells in tunica media were determined using the characteristic light microscopy findings in LIMA. Then, they were compared between the study groups and the respective p-values were obtained (Tab. 2). There was a statistically significant difference in each of these three parameters between the study groups. Furthermore, the total damage score was significantly different between the groups $(p=0.004 *)$. H-scores of tunica intima and tunica media were statistically significantly different between the groups $\left(\mathrm{p}=0.001^{*}\right)$. The immune reactivity was more intense in tunica adventitia in Group II; however, the difference was not significant between the groups $(\mathrm{p}=0.085)$.

\section{Discussion}

U-II is involved in atherosclerosis pathogenesis, restenosis, and pathophysiology of vascular remodelling (9). Urotensin-II is potentiated under the condition of endothelial dysfunction (10). Especially in patients with coronary artery disease and DM, the U-II levels were found out to be high (11). The expression of U-II increases in subendothelial inflammation or in endothelial cells with fibrofatty lesions. This increase in U-II was also observed in the myointimal and foam cells (12). Macrophages transforming into foam cells are involved in the inflammatory processes of atherosclerotic lesions in the intima layer (13). In our study, the CAD patients had mild degeneration and loss in endothelial and some smooth muscle cells in tunica media. In subendothelial areas, we detected foam cells at spaces, indicating the occurrence of atherosclerotic processes. In the $\mathrm{CAD}+\mathrm{DM}$ group, we observed that the endothelial layer of LIMA lost its continuity, endothelial cells were damaged at spaces, and tissue ruptures occurred against the lumen. The vesicles in the apical and basal cell membranes of the endothelial cells were more common as compared to the control group. The subendothelial layer expanded and protruded towards the lumen. We observed increased collagen fibers and disruptions in the undulating pattern of the internal elastic lamina in this layer. Furthermore, fatty streaks originating from the foam cells were present in the subendothelial layer. Moreover, atherosclerosis affected also the tunica media. U-II causes an increase in reactive oxygen species (ROS) synthesis in the smooth muscle cells in $t u-$ nica media. U-II and ROS show synergistic effects in stimulating smooth muscle cell proliferation (14). Oxidized phospholipids cause monocytes to adhere to endothelial cells. These oxidized phospholipids are novel biomarkers with mixed effects on atherosclerosis. They cause chemokine synthesis, stimulate the proinflammatory cytokines and growth factors, suppress leukocyte inflammation, and induce smooth muscle cell proliferation (15). In individuals at risk of developing coronary artery disease, endothelial dysfunction can be easily detected with the oxidative stress index (16). In our study, we observed a more intense U-II immune reactivity in tunica media in CAD patients along with moderate-intensity U-II immune reactivity in tunica intima and tunica adventitia. In the specimens of CAD+DM patients, there was a loss in the morphologic features of smooth muscle cells in tunica media, while invading tunica intima. The immune reactivity was highly intense in tunica intima and tunica media in this group. The positive immunoreactivity was more intense in tunica adventitia compared to the control group. However, the degenerative changes occur in tunica media at a rate of $36.8 \%$ during the preparation of LIMA grafts. These ultrastructural changes and the effects on the vascular tone are reported to affect late-term graft patency. It is suggested that well-controlled dyslipidemia will help maintain the LIMA graft patency in the long term in these patients (17). In this study, we aimed to reduce the risk of injury by preparing pedicled LIMA grafts (5). We followed up the study patients receiving statin therapy in the postoperative period.

As it is known, CABG surgery is also performed in patients younger than 59 years of age (18). The mean age is around 64.8 years in redo CABG surgery patients. Redo coronary artery surgery is associated with higher risks of morbidity and mortality compared to primary CABG (19). In both the diabetic and nondiabetic patients undergoing CABG with the use of IMA on either side of the body, the rates of morbidity/mortality, redo operations, stroke, and renal failure were higher along with the longer duration of ICU stay in diabetic patients as compared to non-diabetic patients (20). According to the patient outcomes in a one-year follow-up, there were no differences in the chest pain, functional capacity, re-hospitalization, and mortality between the groups. This might have occurred because the atherosclerotic process in LIMA does not lead to the development of stenosis severe enough to cause ischemia. Atherosclerosis in LIMA is slow and progressive. In this study, we demonstrated the relationship between U-II and atherosclerotic process in LIMA. Revealing this relationship is important to pave the way for further studies and to gain further insight into the histopathological features occurring in atherosclerosis of LIMA. The description of the relationship between U-II and atherosclerosis in LIMA will contribute to maintaining the long-term patency of the graft. This will reduce the need for redo surgery in patients who underwent CABG at a young age. In particular, high mortality and morbidity in $\mathrm{CAD}+\mathrm{DM}$ patients necessitate the long-term maintenance of arterial grafts used for CABG.

\section{Conclusions}

U-II plays an important role in LIMA atherosclerosis in CAD+DM patients. Prevention of atherosclerotic processes in LIMA will reduce the need for redo CABG and percutaneous coronary interventions (PCI). We suggest that this will increase the quality of life and longevity in patients at advanced ages.

Limitations: In our study, no statistically significant difference was found in terms of the main characteristics of the patients included in the study. The patients were evaluated before and after $\mathrm{CABG}$ and a further clinical follow-up was carried out within one year after the operation. The results of longer follow-up of patients will be evaluated. 


\section{References}

1. Brook R, Detre K. Clinical trials of revascularization therapy in diabetics. Cur Opin Cardiol 2000; 15 (4): 287-292.

2. Windecker S, Kolh P, Alfonso F et al. 2014 ESC/EACTS guidelines on myocardial revascularization: the task force on myocardial revascularization of the European Society of Cardiology (ESC) and the European Association for Cardio-Thoracic Surgery (EACTS) developed with the special contribution of the European Association of Percutaneous Cardiovascular Interventions (EAPCI). Eur Heart J 2014;35: 2541e2619.

3. Watson A, Olukman M, Koilis $\mathbf{C}$ et al. Ürotensin II (UII) receptör antogonism confers vasoprotective effects in diabetes associated aterosclerosis: studies in humans and in a mouse model of diabetes. Diabetologia 2013; 56 (5): 1155-1165.

4. Shiraishi Y, Watanabe T, Suguro T et al. Chronic urotensin II infusion enhances macrophage foam cell formation and atherosclerosis in apolipoprotein E-knockout mice. J Hypertens 2008; 26 (10): 1955-1965.

5. Ozülkü M, Aygün F. Effect of LIMA Harvesting Technique on Postoperative Drainage in Off-Pump CABG. Braz J Cardiovasc Surg 2016;31 (2): $120-126$

6. Ozcan-Kucuk A, Alan H, Gul M et al. Evaluating the Effect of Resveratrol on the Healing of Extraction Sockets in Cyclosporine A-Treated Rats. J Oral Maxillofac Surg 2018; 76 (7): 1404-1413.

7. Gensini GG. A more meaningful scoring system for determining the severity of coronary heart disease. Am J Cardiol 1983; 51: 606.

8. Beypınar İ, Öncel RC, Özdem S et al. The Relationship Between the Level of Parathormone and the Existence and the Degree of Coronary Atherosclerosis Turk J Endocrinol Metab 2018; 22: 237-243.

9. Rodriguez-moyano M, Diaz F, Dionisio M et al. Urotensin II prometes vascular smooth muscle cell proliferation through store-operated calsium entry and EGRF transacvation.Cardiovasc Res 2013; 100 (2): 297-306.
10. Ahmed AH, Maulood IM. Endothelin-1 and angiotensin-II modulate urotensin-II vasoconstriction in rat aorta exposed to mercury. Bratisl Med J 2018; 119 (7) 444-449.

11. Watanbe T, Kanome T, Miyazaki A et al. Human urotensin II as a link between hypertension and coronary artery disesase. Hypertens Res 2006; 29 (6): 375-387.

12. Hassan G, Douglas S, Ohlstein E et al. Expression of urotensin II in human coronary aterosclerosis. Peptides 2005; 26 (12): 2462-2472.

13. Galkina E, Ley K. Immune and inflammatory mechanisms of atherosclerosis. Annu. Rev.Immunol 2009; 27: 165-197.

14. Watanabe T, Arita S, Shiraishi Y et al. Human urotensin II prometes hypertension and atherosclerotic cardiovascular diseases. Curr Med Chem 2009; 16 (5): 550-563.

15. Leonarduzzi G, Gamba $\mathbf{P}$, Gargiulo $\mathbf{S}$ et al. Inflammation-related gene expression by lipid oxidation-derived products in the progression of atherosclerosis. Free Radic Biol Med 2012; 52: 19-34.

16. Karahan O, Manduz S, Bektasoglu G, Zorlu A, Turkdogan KA, Bozok S. A high oxidative stress index predicts endothelial dysfunction in young male smokers. Bratisl Med J 2013; 114 (12): 721-725.

17. Yuan S, Li Y, Ben Y et al. Graft pathology at the time of harvast: impact on long term survival. Rev Bras Cardiovasc 2014; 29 (4): 543-551.

18. Philipp K, Micheal R, Assad $H$ et al. İmpact of age on early outcome after coronary bypass graft surgery using minimized versus conventional exracorporeal circulation. J Cardiothorac Surg 2014; 28 (9): 143.

19. Shin Y, Lee S, Joo H et al. Early and midterm outcome of Redo Coronary Artery Baypass Grafting: On-Pump Versus off-Pump Bypas. Korean J Thorac Cardiovasc Surg. 2014; 47 (3): 225-232.

20. Crawford T, Zhou X, Fraser $\mathbf{C}$ et al. Bilateral internal mammary Artery Use in Diabetic patients: Friend or foe? Ann Thorac Surg 2018; 106 (4): 1088-1094. 